\title{
Application of radar data assimilation on convective precipitation forecasts based on water vapor retrieval
}

\author{
Zhixin $\mathrm{He}^{1,2} \cdot$ Dongyong Wang ${ }^{1} \cdot$ Xuexing $\mathrm{Qiu}^{1} \cdot$ Yang Jiang ${ }^{1} \cdot \mathrm{Huimin}^{\mathrm{Li}} \mathrm{i}^{1} \cdot$ Aiqing Shu ${ }^{3}$
}

Received: 1 April 2020 / Accepted: 6 October 2020 / Published online: 4 January 2021

(c) The Author(s) 2021

\begin{abstract}
Based on a short-time heavy rainfall in Anhui and the weather research and forecasting (WRF) model, the water vapor in the initial field of the model is retrieved using the statistical relationships of the reflectivity factor from the Doppler weather radar with the relative humidity and hydrometeor. Three-dimensional variational (3DVAR) assimilation method is used to assimilate the radar reflectivity factor and radial velocity, and then the impact of assimilating retrieved water vapor on the analysis and forecast of the torrential rain is assessed. The results show that, after assimilating the retrieved water vapor, the water vapor field in the model is significantly improved. The water vapor content in the middle layer of the model in the analyzed field is increased, corresponding well with the convective region. Meanwhile, the precipitation distribution during this weather process is successfully simulated. The mesoscale characteristics are better presented by the imageries of radar reflectivity factor, and false echoes are partially reduced. Besides, the prediction of short-time heavy rainfall regions is closer to the actual observations. After assimilating the retrieved water vapor, the simulated one-hour accumulated rainfall is closer to the actual observation, and the fraction skill score (FSS) is higher.
\end{abstract}

\section{Introduction}

Short-time heavy rainfall is an important meteorological disaster, and the accurate forecast will help to prevent and reduce such disasters and ensure the safety of people"s lives and property. However, due to the short forecast lead-time and strong rainfall intensity, the accuracy of short-time heavy precipitation forecast is still a huge challenge in operational forecast. At present, the forecasts of short-time heavy precipitation are mainly made by meso- and smallscale numerical models, whose accuracy mainly depends on improving the accuracy of the initial field. The data assimilation is one of the methods to effectively improve the initial conditions in the numerical weather prediction

Responsible Editor: Xiang-Yu Huang.

Xuexing Qiu

qiuxuexing@126.com

1 Anhui Meteorological Bureau, Anhui Meteorological Observatory, Hefei, China

2 Shanghai Typhoon Institute of China Meteorological Administration, Shanghai, China

3 Nanjing University of Information Science and Technology, Nanjing, China
(NWP) model. And the Doppler weather radar is one of the important observation platforms for meso- and small-scale weather systems. Therefore, the effective assimilation of Doppler weather radar observations is of great significance for improving the accuracy of short-time heavy rainfall forecasts.

In the past 30 years, great progresses have been made in assimilating the remote sensing observations. meanwhile experts and scholars have developed a variety of advanced data assimilation methods, mainly including variational data assimilation (Parrish and Derber 1992; Courtier et al. 1994; Gauthier et al. 1999; Lorenc and Coauthors 2000; Huang et al. 2009; Meng Zhang et al. 2011; Xu et al. 2013, 2019a, b; Honda et al. 2005; Zupanski et al. 2005; Huang et al.2009; Shen et al. 2019a), ensemble Kalman filter (En KF) data assimilation and hybrid data assimilation (Wang et al. 2008a, b; Wang 2011; Xu et al. 2015a, b, 2016a, Zhang and Zhang 2012; Li et al. 2012; Shen and Min 2015, 2016; Shen et al. 2017a, b, 2019b).

The variational data assimilation method includes threedimensional variational (3DVAR) and four-dimensional variational (4DVAR) methods, which are widely used in the simulation of convective storms and the improvement of precipitation prediction. For example, Sun and Crook (1997) applied the 3DVAR method to the assimilation of 
radial velocity and reflectivity from the Doppler radar in a cloud model and its adjoint model; thus, the structural characteristics of wind field, thermal field and micro-physical field in convective storms can be retrieved. Kuo et al. (2005) used the 3DVAR method to assimilate the radial velocity and reflectivity of the Doppler radar in the MM5 model, improving the quantitative precipitation forecast. Gao et al. $(2004,2012)$ used the 3DVAR method to assimilate the reflectivity of Doppler radar and achieved good results in simulating super storms. Montmerle and Faccani (2009) also used the 3DVAR assimilation technique to assimilate radial velocity from Doppler radars of the French ARAMIS (Application Radar la Météorologie Infra Synoptique) network. They found a positive impact of radar wind data on the analysis and forecast of precipitation. Soichirow et al. (2009) improved the quantitative precipitation prediction by assimilating the Doppler radar data through the cloud analysis in the 3DVAR assimilation system of WRF. Wang et al. (2013a) indirectly assimilated the radar reflectivity using 3DVAR method in WRF. It was concluded that the assimilation of reflectivity increases the humidity, rainwater, and convective available potential energy (CAPE) in the convective region. At the same time, they also developed a 4DVAR assimilation scheme for assimilating the radar reflectivity and radial velocity in WRF (Wang et al. 2013b). Sun and Wang (2013) used 4DVAR method to assimilate the radial velocity and reflectivity of the Doppler radar for more accurately analyzing the low-level cold pools, leading-edge convergence and mid-level latent heat of squall line systems.

In recent years, the assimilation method of EnKF has been also widely used. The use of EnKF to assimilate radar observation data and radial velocities can improve the forecast of convections and the simulation of severe storms, respectively (Zhang et al. 2004; Tong and Xue 2005; Dowell et al. 2011; Tanamachi et al. 2013;). Assimilating the Doppler radial velocity through EnKF can improve the forecast accuracy of typhoon intensity and moving-track (Zhang et al. 2009). In the National Severe Storms Laboratory (NSSL) Collaborative Model for Multi-scale Atmospheric Simulation (NCOMMAS), the EnKF method is used to assimilate the radar data. The third method is the hybrid data assimilation method. Many scholars have confirmed that using the variational and ensemble methods to assimilate the Doppler radar data can improve the initial field of the model (Wang et al. 2013a, b, c; Gao and Stensrud 2014; Gao et al. 2016; Wang and Wang 2017).

Many studies have demonstrated that temperature and humidity in the initial field of the model play an important role in the analysis and prediction of the storm scale (Ge et al. 2013). However, Doppler weather radars cannot directly observe the model variables, because the radar radial velocity only represents partial information about the wind field. Besides, there are no direct observations of water vapor mass mixing ratio and the content of hydrometeors from radar data. Thereby, it is necessary to assimilate radar reflectivity data using the corresponding relation between water vapor and the reflectivity factor, and this method is more and more used. For example, the 3DVAR method assimilates the retrieved one-dimensional relative humidity profile (Caumont et al. 2010; Wattrelot et al. 2014); 3DVAR method assimilates the rainwater and water vapor retrieved from radar reflectivity factor data (Wang et al. 2013a, b); during the cloud analysis process, the relative humidity, water vapor mixing ratio and temperature of the model are adjusted based on radar, satellite and ground observation data (Xue et al. 2003; Zhang 1999; Brewster 2015; Hu et al. 2006; Schenkman et al. 2011). According to the vertical integrated liquid (VIL) water content of radar, 3DVAR assimilation is used to retrieve the water vapor (Lai et al. 2019). In this study, the statistical relationship between the radar reflectivity factor and relative humidity is used to retrieve water vapor content in the initial field. Combined with the 3DVAR of Weather Research and Forecasting model assimilation system (hereinafter referred to as WRF-3DVAR), the radar data assimilation experiments with retrieved water vapor and hydrometer in the initial field are carried out. The effect of assimilating the retrieved water vapor and hydrometer in the initial field on the simulation of short-time heavy rainfall is studied.

\section{Methods}

\subsection{WRF-3DVAR}

WRF-3DVAR is used to solve a quadratic functional minimization problem (Lorenc) for the deviation between the analysis field and observation field and that between the analysis field and background field. The functional is defined as follows.

$J(x)=\frac{1}{2}\left[\left(x-x_{b}\right)^{T} B^{-1}\left(x-x_{b}\right)+\left(H(x)-y_{0}\right)^{T} O^{-1}\left(H(x)-y_{0}\right)\right]$,

where $x$ represents the analysis field; $x_{b}$ represents the background field; $y_{0}$ represents the observation field; $B$ is the covariance matrix of background errors; $O$ is the covariance matrix of observation errors; $\mathrm{y}=H(x)$ is observation equivalence of analysis variables; $H$ is the observation operator, which may be a simple interpolation operator or a complex one. For the radial velocity data from radar observations, the observation operators include the spatial interpolation operators and the physical conversion process. The primary goal of the 3DVAR system is to solve the minimum value of the above objective function through an iterative method, so as to obtain an estimate value close to the true state of 
the atmosphere as possible. In the calculation process of variational minimization, the inverse matrixes of the observation-error covariance and the background-error covariance are used. It is generally considered that the observations are uncorrelated, and $O$ is a diagonal matrix or a near-diagonal matrix, whose inverse matrix is not difficult to find.

\subsection{2 Observation operator for assimilating the radar radial velocity}

The radar radial velocity is not a direct observation variable in the model. An observation operator needs to be established to link the horizontal and vertical velocity in the model with the radial wind velocity from the radar. The observation operator for the Doppler radar radial velocity in WRF-3DVAR is calculated as follows (Sun et al. 1997; Sun et al. 1998).

$V_{r}=u \frac{x-x_{i}}{r_{i}}+v \frac{y-y_{i}}{r_{i}}+\left(w-v_{T}\right) \frac{z-z_{i}}{r_{i}}$,

where $u, v$ and $w$ are the model wind components; $x, y$ and $z$ represent the location of radar station; $x_{i}, y_{i}$ and $z_{i}$ denote the location of radar observation; $r_{i}$ is the distance between the observation site and the location of radar; $v_{T}\left(\mathrm{~m} \mathrm{~s}^{-1}\right)$ is the terminal velocity, and $v_{T}$ of precipitation particles must be considered during the radar volume scanning at each angle of elevation. The calculation of $v_{T}$ takes the following form.

$v_{T}=5.40 v q_{r \alpha}^{0.125}$

where $q_{r \alpha}$, is the mixing ratio of rainwater, and $v$ is the correction factor, which is defined as follows.

$v=\left(\frac{p_{0}}{\bar{p}}\right)^{0.4}$,

where $\bar{p}$, is the background pressure, and $p_{0}$, is the surface pressure $(1000 \mathrm{hPa})$. To make it possible to assimilate the radar radial velocity in the WRF-3DVAR system, the horizontal wind can be decomposed into a potential function and a stream function.

\subsection{Forward operator for assimilating the radar reflectivity}

The forward operator of radar reflectivity factor in WRF3DVAR is obtained by calculating the mixing ratios of three hydrometeors, including rain $\left(q_{r a}\right)$, snow $\left(q_{s n}\right)$ and graupel $\left(q_{g r}\right)$ (Lin et al. 1983; Gilmore et al. 2004; Dowell et al. 2011). And the equivalent radar reflectivity $\left(Z_{e}\right)$ is the reflectivity sum of these three hydrometeors. The formula is as follows,
$Z_{e}=Z\left(q_{r a}\right)+Z\left(q_{s n}\right)+Z\left(q_{g r}\right)$.

Since the reflectivity factor in Eq. (5) is assumed to be a function of the three hydrometeors' mixing ratios, the assimilation of the reflectivity may make the mixing ratios of hydrometeors more uncertain (e.g., the rainwater mixing ratio may appear at the upper level in the initial field of model). To reduce the uncertainty, the forward operators based on the temperature in the background field are applied (Gao and Stensrud 2012) with the following formula.

$Z_{e}=\left\{\begin{array}{l}T_{b}>5^{\circ} C \\ Z\left(q_{s n}\right)+Z\left(q_{g r}\right) T_{b}<-5^{\circ} C \\ \alpha Z\left(q_{r a}\right)+(1-\alpha)\left[Z\left(q_{s n}\right)+Z\left(q_{g r}\right)\right]-5^{\circ} C<T_{b}<5^{\circ} C\end{array}\right.$

where $T_{b}$ is the background temperature, while it varies in the range from $-5{ }^{\circ} \mathrm{C}$ to $5^{\circ} \mathrm{C}, \alpha$ varies linearly between 0 and 1 . Gao and Stensrud (2012) found that while assimilating the radar reflectivity, the correction of Eq. (6) is more accurate and the hydrometeor profile can be effectively obtained.

\subsection{Water vapor retrieval}

\subsubsection{Retrieval method}

In previous stues, for adjusting the water vapor, a common method is to set the background relative humidity $(R H)$ as a fixed threshold $(R H=95, R H=100$, etc. $)$ in the model, and to calculate the water vapor with $q_{v}=q_{s} \times R H$. Among them, $q_{s}$ is the saturation specific humidity of the atmosphere, which is calculated with the functional relationship between the air pressure and temperature at the model levels, while $q_{v}$ is the water vapor $\left(\mathrm{g} \mathrm{kg}^{-1}\right)$. However, actual meteorological observations show that when precipitation occurs, the relative humidity is not necessarily $100 \%$, which can change from 80 to $100 \%$. Only in the heavy fog, the air relative humidity near the ground can reach saturation. Therefore, based on the statistical relationship between the radar reflectivity factor $(Z ; \mathrm{dBZ})$ and the relative humidity $(R H ; \%)$ in East China, the relative humidity in the model is calculated and the water vapor is adjusted, as shown in Table 1. To distinguish the effective precipitation echo from the clear-air echo, this study selects the echo exceeding $25 \mathrm{dBZ}$ as the effective precipitation echo, and the clear-air echo is considered below $20 \mathrm{dBZ}$. For the region with reflectivity factor exceeding $25 \mathrm{dBZ}$, the relative humidity is calculated with $R H=f(Z)$ and $f(Z)$ is given in Table 1. For the region with reflectivity below $20 \mathrm{dBZ}$, the relative humidity is calculated with $R H=\min \left(R H_{b}, 50\right)\left(R H_{b}\right.$ is the relative humidity of the background field). While adjusting the water vapor, Eq. (5) and Eq. (6) need to be used to retrieve the 
Table 1 Statistical relationship between $Z(\mathrm{dBZ})$ and $R H(\%)$

\begin{tabular}{ll}
\hline Temperature & $\begin{array}{l}\mathrm{RH}=\mathrm{f}(\mathrm{Z})(\text { Rela- } \\
\text { tionship function) }\end{array}$ \\
\hline$<5{ }^{\circ} \mathrm{C}$ & $\mathrm{RH}=95, \mathrm{Z}>25$ \\
$5.0-19.8{ }^{\circ} \mathrm{C}$ & $\mathrm{RH}=91.8+0.12 \mathrm{Z}$ \\
$19.9-22.9{ }^{\circ} \mathrm{C}$ & $\mathrm{RH}=89.2+0.14 \mathrm{Z}$ \\
$23.0-25.9{ }^{\circ} \mathrm{C}$ & $\mathrm{RH}=84.8+0.17 \mathrm{Z}$ \\
$26.0-26.9{ }^{\circ} \mathrm{C}$ & $\mathrm{RH}=79.2+0.22 \mathrm{Z}$ \\
$27.0-28.2{ }^{\circ} \mathrm{C}$ & $\mathrm{RH}=74.5+0.27 \mathrm{Z}$ \\
$28.2-29.9{ }^{\circ} \mathrm{C}$ & $\mathrm{RH}=69.2+0.28 \mathrm{Z}$ \\
$>29.9^{\circ} \mathrm{C}$ & $\mathrm{RH}=83.7+0.28 \mathrm{Z}$
\end{tabular}

hydrometeor content. To distinguish the hydrometeor content in the precipitation area and the clear-air area, we set that for the observation stations with reflectivity exceeding $25 \mathrm{dBZ}$, the retrieved hydrometeor in the model initial field is obtained according to Eq. (5) and Eq. (6). For the observation stations with reflectivity lower than $20 \mathrm{dBZ}$, the hydrometeor content $\left(q_{\text {hydrometer }}\right)$ is determined by $q_{\text {hydrometer }}=\min$ $\left(q_{\text {hydrometer }}, q_{\text {hydrometer_b }}\right) . q_{\text {hydrometer }}$ is the retrieved hydrometeor content according to Eq. (5) and Eq. (6), and $q_{\text {hydrometer_b }}$ is the hydrometeor content in the model background field.

\subsubsection{Evaluation of retrieval the scheme}

The vertical water vapor profile at the point $\left(115.57^{\circ} \mathrm{E}\right.$, $32.67^{\circ} \mathrm{N}$ ) is retrieved at $1200 \mathrm{UTC}$ on July 26th, 2018. In the Fig. 1, comparing with the vertical water vapor profile of sounding observations at neighboring point, it can be seen that the water vapor adjustment area in our current study is mainly about $850-500 \mathrm{hPa}$.

The water vapor content from 850 to $500 \mathrm{hPa}$ in the retrieval experiment is larger than the observation, the

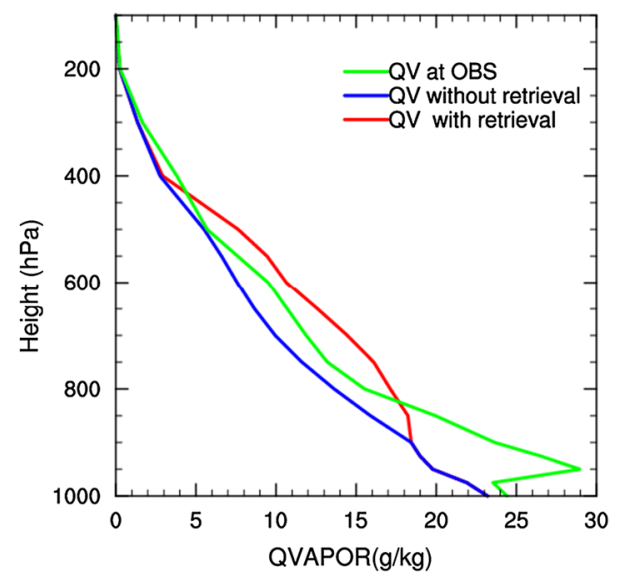

Fig. 1 The vertical water vapor profile at 1200 UTC on July 26th, 2018 at the point $\left(115.57^{\circ} \mathrm{E}, 32.67^{\circ} \mathrm{N}\right)$ average error is $1.41 \mathrm{~g} / \mathrm{kg}$ and the standard deviation of $5.45 \mathrm{~g} / \mathrm{kg}$. Then the water vapor content of the no retrieval experiment is smaller than the observation, The average error is $-2.13 \mathrm{~g} / \mathrm{kg}$, and the standard deviation is $5.52 \mathrm{~g} / \mathrm{kg}$ from 850 to $500 \mathrm{hPa}$.

\section{Case selection, data and numerical experiments}

\subsection{The rainstorm on July 26 th, 2018 and radar data processing}

A rainstorm in the warm sector occurred in Anhui on July 26th, 2018. The torrential rainfall mainly occurred during 1200 UTC-1500 UTC on July 26th with the hourly accumulated precipitation of nearly $100 \mathrm{~mm}$, causing urban water accumulation and traffic congestion. From the analysis of the weather situation chart (Fig. 2), the Anhui area was controlled by the subtropical high at 1200 UTC on July 26th, and ordinarily, precipitation is not easy to occur. Therefore, neither the global-scale numerical forecast nor the regional mesoscale numerical forecast could predict this precipitation process.

In this study, the radar observation data are from the Doppler weather radars in Hefei of Anhui Province and Nanjing of Jiangsu Province. This is a new-generation S-band Doppler weather radar independently developed by China, and its performance is close to the WSR-88D radar in the U.S. Considering that the Doppler radar network is still constructing in China, there is no unified software or platform to process the radar-based observation data. Therefore, it is necessary to carry out the quality control before inputting the radar observation data to numerical models. The quality control mainly includes the following steps. (1) Since the gradient of the ground clutter echo intensity $\left(G_{\mathrm{dBZ}}\right)$ is strong in the vertical direction, it can be

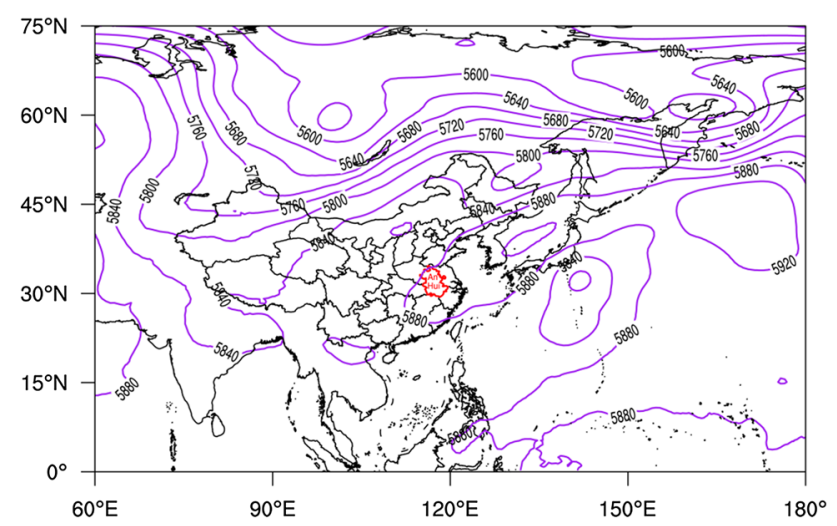

Fig. 2 500-hPa geopotential height field at 1200 UTC on July 26th, 2018 
used to remove the ground clutter. $G_{\mathrm{dBZ}}=\mathrm{Z}_{\mathrm{LOW}}-\mathrm{Z}_{\mathrm{UP}}\left(Z_{\mathrm{LOW}}\right.$ is the radar reflectivity at a certain elevation and position, and $Z_{\mathrm{UP}}$ is the reflectivity at this position corresponding to the upper elevation). The threshold is determined as $30 \mathrm{dBZ}$, and if $G_{\mathrm{dBZ}}>30 \mathrm{dBZ}$, the observations are eliminated. (2) The points with the isolated reflectivity factor or the radial velocity are removed: when the number of valid observations in the range of $3^{\circ} \times 3 \mathrm{~km}$ around this point is counted, if the number is less than 4 , the observation at this point is eliminated. (3) The average value and the standard deviation of each observation in the range of $3^{\circ} \times 3 \mathrm{~km}$ around this point on the same cone are calculated. When the standard deviation is larger than $20\left(\mathrm{~m} \mathrm{~s}^{-1}\right.$ or $\mathrm{dBZ}$ ), the observation data at this point are considered as discontinuous and then eliminated. (4) Observations of radar radial wind less than $2 \mathrm{~m} \mathrm{~s}^{-1}$ are eliminated. (5) Observations of the reflectivity factor less than $25 \mathrm{dBZ}$ are eliminated.

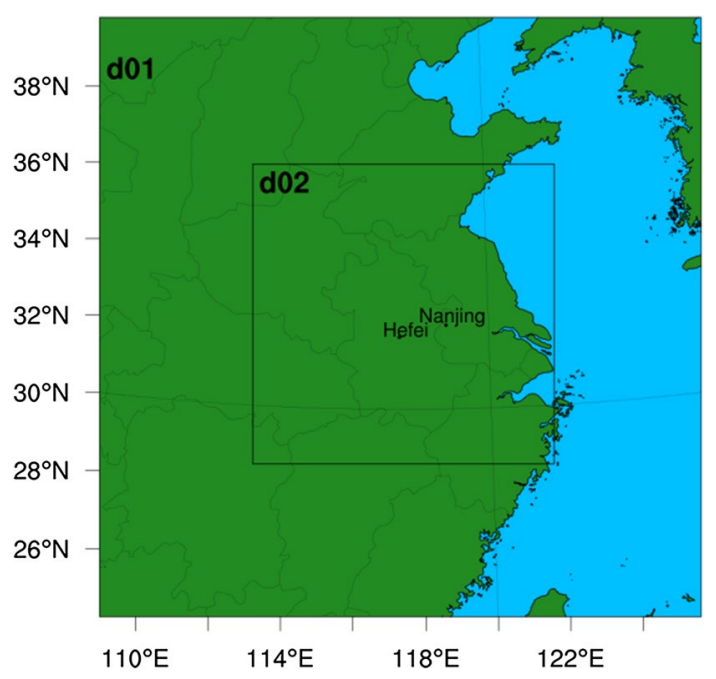

Fig. 3 Simulation domain and radar locations

\subsection{Experimental design}

The experiments use the WRFV3.8, which is a compressible non-hydrostatic mesoscale model, with $50 \mathrm{hPa}$ as the top layer. The model adopts double-domain nesting, with the grids of $193 \times 193$ in the outer domain and the grids of $289 \times 289$ in the inner domain. The horizontal resolution is $9 \mathrm{~km}$ and $3 \mathrm{~km}$, respectively. The number of vertical layers is 35 , and the integration time-step is $45 \mathrm{~s}$. The range of the simulation area is shown in Fig. 3. Since the inner domain has been refined to the cloud scale, the cumulus convection parameterization scheme is not selected. The main physical parameterization schemes include Mellor-Yamada-Janjic (MYJ) boundary layer scheme, the WRF Single-Moment 6-class (WSM6) microphysics scheme, Rapid Radiative Transfer Model (RRTM) long-wave radiation scheme and Dudhia short-wave radiation scheme. The initial field and lateral boundary conditions in the model are from the reanalysis data with a resolution of $0.25^{\circ} \times 0.25^{\circ}$ provided by the European Centre for Medium-Range Weather Forecasts (ECWMF). The covariance of the background error is calculated by the National Meteorological Center (NMC) method. The experimental design and flowchart are shown in Table 2; Figs. 4, 5, respectively.

The five experiments used for the comparative research in this study are CTRL experiment, RV_RF_S experiment, RV_RF_QV_S experiment, RV_RF_Cycle experiment and RV_RF_QV_Cycle experiment. The CTRL experiment is a benchmark experiment without assimilating any observation data. In the RV_RF_S experiment, the Doppler radar radial wind observation data are directly assimilated and the radar reflectivity factor observation data is single indirectly assimilated through the single WRF-3DVAR. Configuration of the RV_RF_QV_S experiment is similar to that of the RV_RF_S experiment. The only difference is that at the initial time of the analysis, before assimilating the radar radial velocity and reflectivity factors, the QV was adjusted based on the observed radar reflectivity factors. CTRL experiment,

Table 2 Experimental design

\begin{tabular}{|c|c|c|c|}
\hline Serial number & Experiment name & Experiment scheme & $\begin{array}{l}\text { Assimi- } \\
\text { lation } \\
\text { cycling }\end{array}$ \\
\hline Exp1 & CTRL & Radar data unassimilated & No \\
\hline Exp2 & RV_RF_S & $\begin{array}{l}\text { (1) Assimilation of radar radial velocity } \\
\text { (2) Indirect assimilation of radar reflectivity factor }\end{array}$ & No \\
\hline Exp3 & RV_RF_QV_S & $\begin{array}{l}\text { (1) Assimilation radar radial velocity } \\
\text { (2) Indirect assimilation of radar reflectivity factor } \\
\text { (3) Water vapor adjustment }\end{array}$ & No \\
\hline Exp4 & RV_RF_Cycle & $\begin{array}{l}\text { (1) Assimilation radar radial velocity } \\
\text { (2) Indirect assimilation radar reflectivity factor }\end{array}$ & Yes \\
\hline Exp5 & RV_RF_QV_Cycle & $\begin{array}{l}\text { (1) Assimilation radar radial velocity } \\
\text { (2) Indirect assimilation radar reflectivity factor } \\
\text { (3) Water vapor adjustment }\end{array}$ & Yes \\
\hline
\end{tabular}




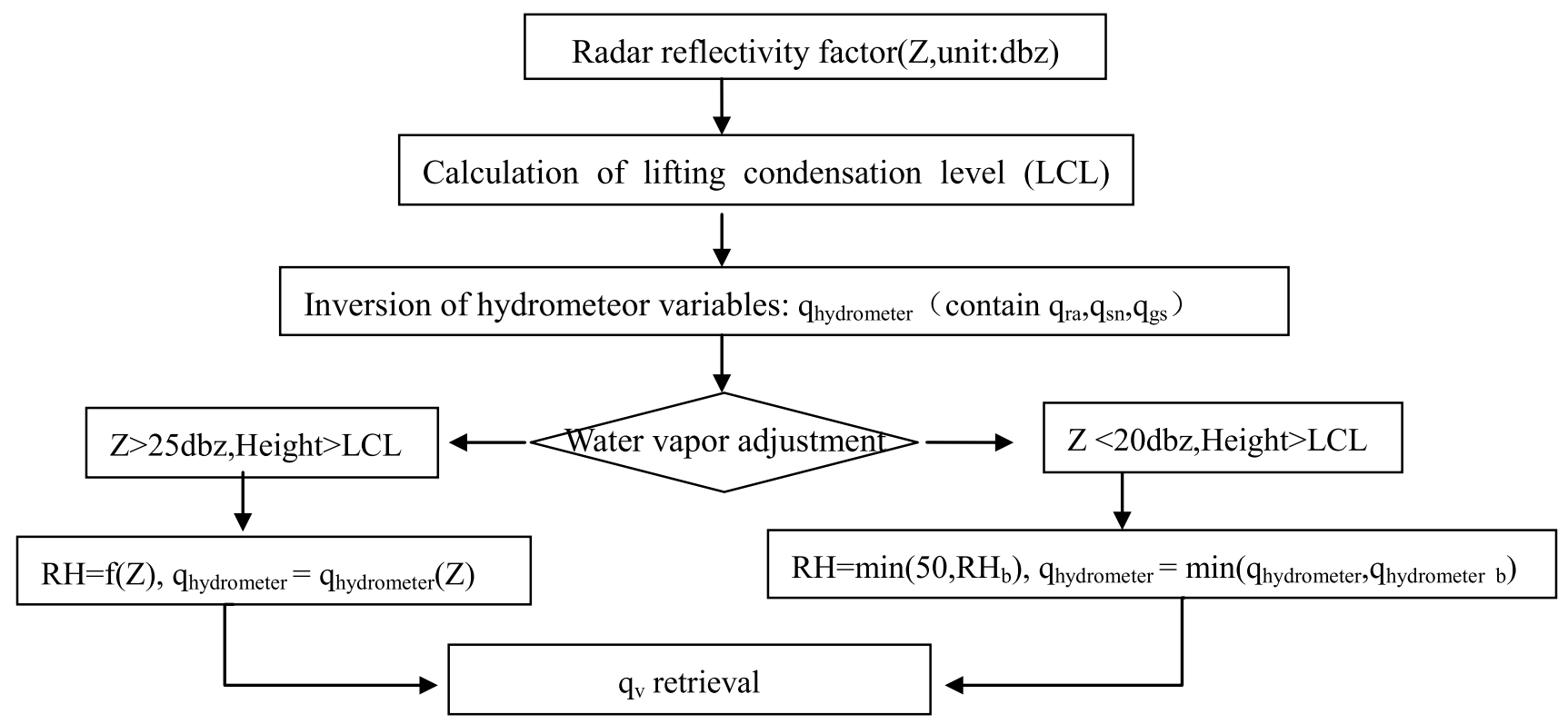

Fig. 4 Flow chart of qv retrieval

\begin{tabular}{|c|c|c|c|}
\hline $\mathrm{q}_{\mathrm{v}}$ retrieval $+3 \mathrm{DVAR}$ & $\mathrm{q}_{\mathrm{v}}$ retrieval $+3 \mathrm{DVAR}$ & $\mathrm{q}_{\mathrm{v}}$ retrieval $+3 \mathrm{DVAR}$ & \\
\hline & & & data assimulation \\
\hline $\begin{array}{l}12: 00 \\
\text { cold start }\end{array}$ & $\begin{array}{l}13: 00 \\
\text { cycle }\end{array}$ & $\begin{array}{l}14: 00 \\
\text { cycle }\end{array}$ & $\begin{array}{cc}15: 00 & \text { time } \\
\text { ending time } & \end{array}$ \\
\hline
\end{tabular}

Fig. 5 Flow chart of cycling assimilation

RV_RF_S experiment, RV_RF_QV_S experiment are cold start from 12:00 to 15:00. The RV_RF_Cycle experiment and RV_RF_QV_Cycle experiment are used to discuss the effect of water vapor adjustment for the assimilation and forecasts after the hot start of the model, so as to evaluate the influence of the water vapor adjustment scheme on the simulation results in the assimilation cycling of radar data. The RV_RF_Cycle experiment takes the time of 1200 UTC on July 26th, 2018 as the initial analysis time, and the observation data (radar radial velocity and reflectance factor) is assimilated every hour until 1400 UTC on July 26, 2018. The analysis field at the last time is taken as the background field for the 3-h deterministic prediction. The RV_RF_QV_Cycle experiment adds water vapor adjustment based on the $\mathrm{RV}_{-}$ RF_Cycle experiment, and then assimilates the observation data of radar radial velocity and reflectivity factor every hour, so that the water vapor in the initial field of model corresponds to the observed reflectivity factor as much as possible.

The $\mathrm{RV}+\mathrm{RF}+\mathrm{QV}$ assimilation cycling experiment designed here is to verify the effect of water vapor adjustment cycling and assimilating radar radial velocity and radar reflectivity factor for the rainfall simulation. Figure 5 shows a flowchart of this scheme.

\section{Results}

As can be seen from the above sections, a single cold start assimilation and assimilation cycling are designed in this study to evaluate the influence of water vapor adjustment in the initial field and the different assimilation methods of radar reflectivity factors on the analysis and forecast of this rainstorm. Chapters are arranged as follows. In Sects. 4.1.1-4.1.4, the effects of the single assimilation at 1200 UTC on July 26th, 2018 in the CTRL, RV_RF_S and RV_RF_QV_S experiments are analyzed. And in Sects. 4.2.1-4.2.4, the effects of hourly assimilation cycling in the RV_RF_Cycle and RV_RF_QV_ Cycle experiments are analyzed.

\subsection{Analysis of assimilation experiment with single cold start}

\subsubsection{Water vapor content in the initial field}

The humidity information in the initial field of the numerical model often plays a key role in the accurate prediction of the rainstorm system. In this section, we analyze the effects of 
the single assimilation in the cold start model after the water vapor adjustment. Figure 6 shows the distribution of water vapor increments in the 11th level of the model on July 26th, 2018. It can be found that in the RV_RF_QV_S experiment after adjusting the water vapor based on the radar reflectivity factor, the water vapor content in the key area of convection increases significantly, and the area of increase is roughly consistent with the actually observed convection area, with a maximum value of $11.8 \mathrm{~g} \mathrm{~kg}^{-1}$. While the water vapor increment in the RV_RF_S experiment is about $7.8 \mathrm{~g} \mathrm{~kg}^{-1}$, which has a phase deviation from the actual observed convection area.

\subsubsection{Simulation based on the single assimilation of radar reflectivity}

To some extent, the echo intensity reflects the distribution of water vapor in the atmosphere that has not landed on the ground. Therefore, the accuracy of echo intensity analysis plays a very important role in the forecast of short-time heavy precipitation. Figure 7 shows the hourly composite reflectivity factor from the analysis and prediction of each experiment. First, from Fig. $7 b 1$ to b4, it can be found that the CNTL experiment could hardly predict the heavy precipitation process. Compared with the CNTL experiment, the RV_RF_S experiment successfully analyzed some heavy rainbands, but compared with the observation, the position of them still showed a large deviation. Then, by comparing Fig. 7a 1 and $\mathrm{d} 1$, it can be seen that the composite reflectivity factor analyzed by the RV_RF_QV_S experiment after the water vapor adjustment is substantially the same as the observed reflectivity factor. For the forecast in the following $3 \mathrm{~h}$, the composite reflectivity factor analyzed by the RV_RF_QV_S experiment is consistent with the observation, but the magnitude is larger. Third, from the comparison between Fig. $7 \mathrm{a} 2$ and $\mathrm{d} 2$, we can see that the positions of simulated convection echoes at $\mathrm{A}, \mathrm{B}, \mathrm{C}$, and $\mathrm{D}$ in $\mathrm{RV}$ RF_QV_S experiment are consistent with the observations, while the simulated intensity is stronger than the observations. But the new-generated isolated echoes at $\mathrm{E}$ and $\mathrm{F}$ are not successfully predicted, and false echoes are predicted at G. Fourth, by comparing Fig. 7a3 and d3, the analysis region of echoes greater than $25 \mathrm{dBZ}$ is wider than observed, the strong echo at $\mathrm{A}$ is further east and stronger, and the strong echo at B is not generated. Finally, from the comparison between Fig. 7a4 and d4, it can be easily concluded that for the region of echoes greater than $25 \mathrm{dBZ}$, the range of maximum reflectivity factor analyzed by the RV_RF_QV_S experiment is larger than that observed, the strong echo at $\mathrm{A}$ is further north, and the strong echo at B is not generated.

\subsubsection{Forecast performance of single assimilation for precipitation}

The previous section has analyzed the water vapor field and composite reflectivity factors. In this section, we will further evaluate the impact of water vapor adjustment and radar data assimilation on the analysis and prediction of this precipitation process. Seen from Fig. 8a1-c3, the CNTL and RV_RF_S experiments did not simulate the heavy precipitation process successfully; thus, they may have no ability to predict heavy precipitation. However, by comparing Fig. 8a1, d1, we can see that for the accumulated precipitation forecast at 12:00-13:00 on July 26th, 2018 from the RV_RF_QV_S experiment, the predicted regions of heavy rainfall are basically consistent with the actual observation precipitation for the three convective systems, but the predicted intensity is significantly stronger; for the accumulated precipitation forecast at 13:00-14:00 on July 26th, 2018, Fig. 8a2, d2 show that the heavy rainfall region coincides with the actual observation, but the predicted intensity is significantly stronger; and for the accumulated precipitation forecast at 13:00-14:00 on July 26th, 2018, seen from Fig. 8a3, d3, the north-south rainband predicted by the RV_RF_QV_S experiment is slightly further east than the observation,
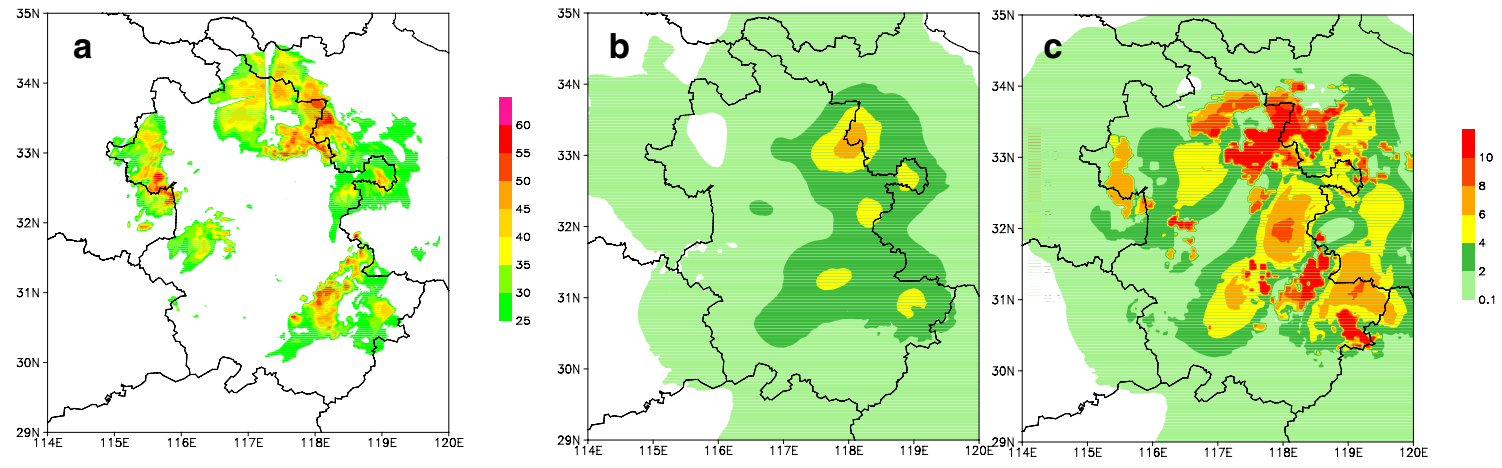

Fig. 6 Water vapor increment on the 11th level at 1200 UTC on July 26th, 2018. a Maximum reflectivity observed at 1200 UTC, (b) RV_RF_SCTRL and (c) RV_RF_QV_S-CTRL 

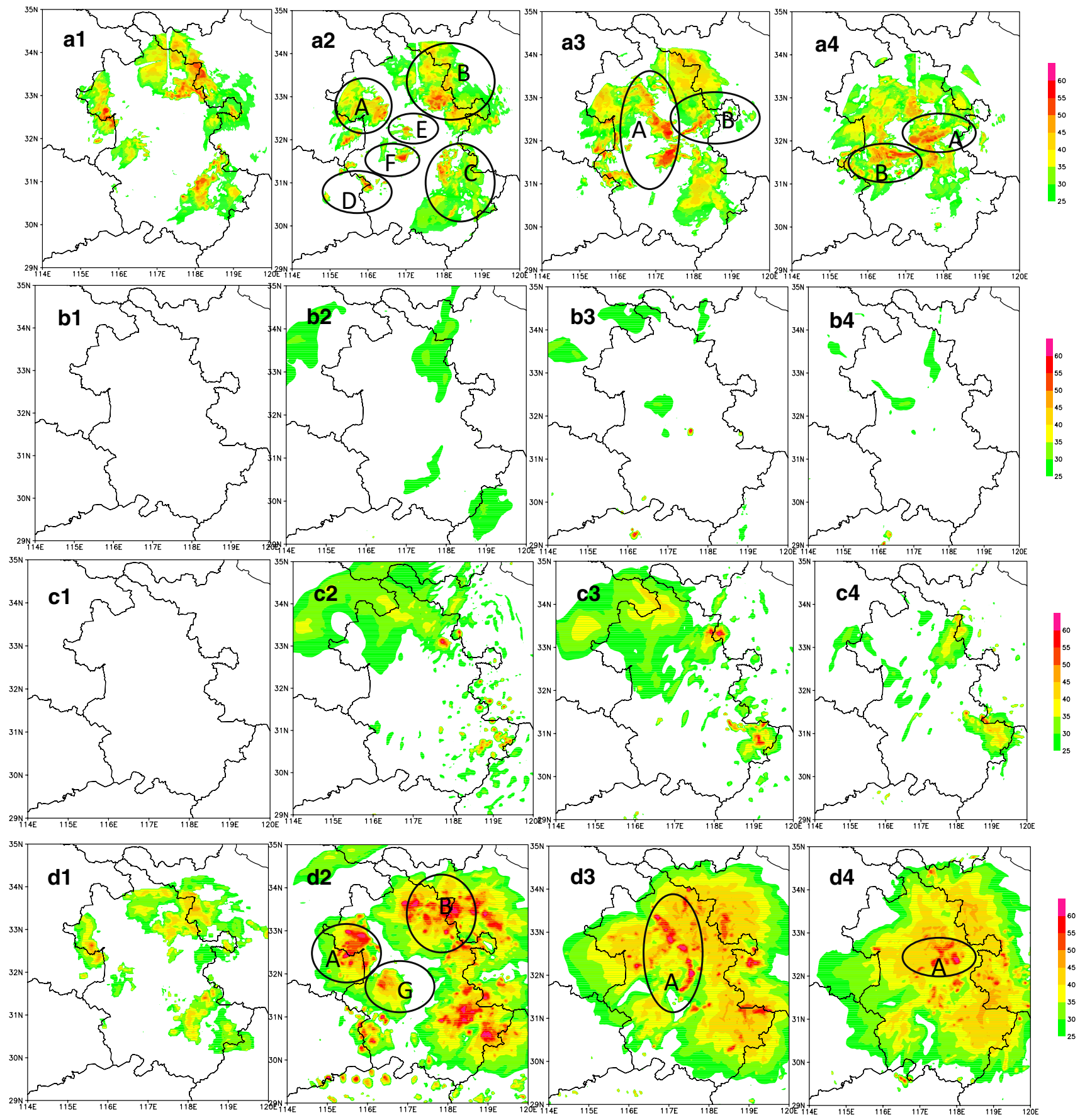

Fig. 7 Observations and forecasts of hourly maximum reflectivity. (1, 2, 3 and 4 denote the reflectivity at 1200 UTC, 1300 UTC, 1400 UTC and 1500 UTC, respectively. a, b, $\mathbf{c}$ and $\mathbf{d}$ denote the observation, CNTL experiment, RV_RF_S experiment and RV_RF_QV_S, respectively)

and the intensity is equivalent. However, the forecast of east-west rainband is of low accuracy.

\subsubsection{Objective verification of precipitation forecast}

4.1.4.1 a Verification method In this section, we use the fraction skill score (FSS), threat score (TS) and bias score (BIAS) to quantitatively verify the simulation results of the three groups of experiments (Roberts and Lean 2008). The basic principle is to calculate the probability value of the central grid point of the window region in the study area, that is, the ratio of grid points exceeding a certain threshold to the total grid points in the window region, thereby transforming the prediction field and the observation field into a probability distribution field of grids. The FSS is then defined as follows. 

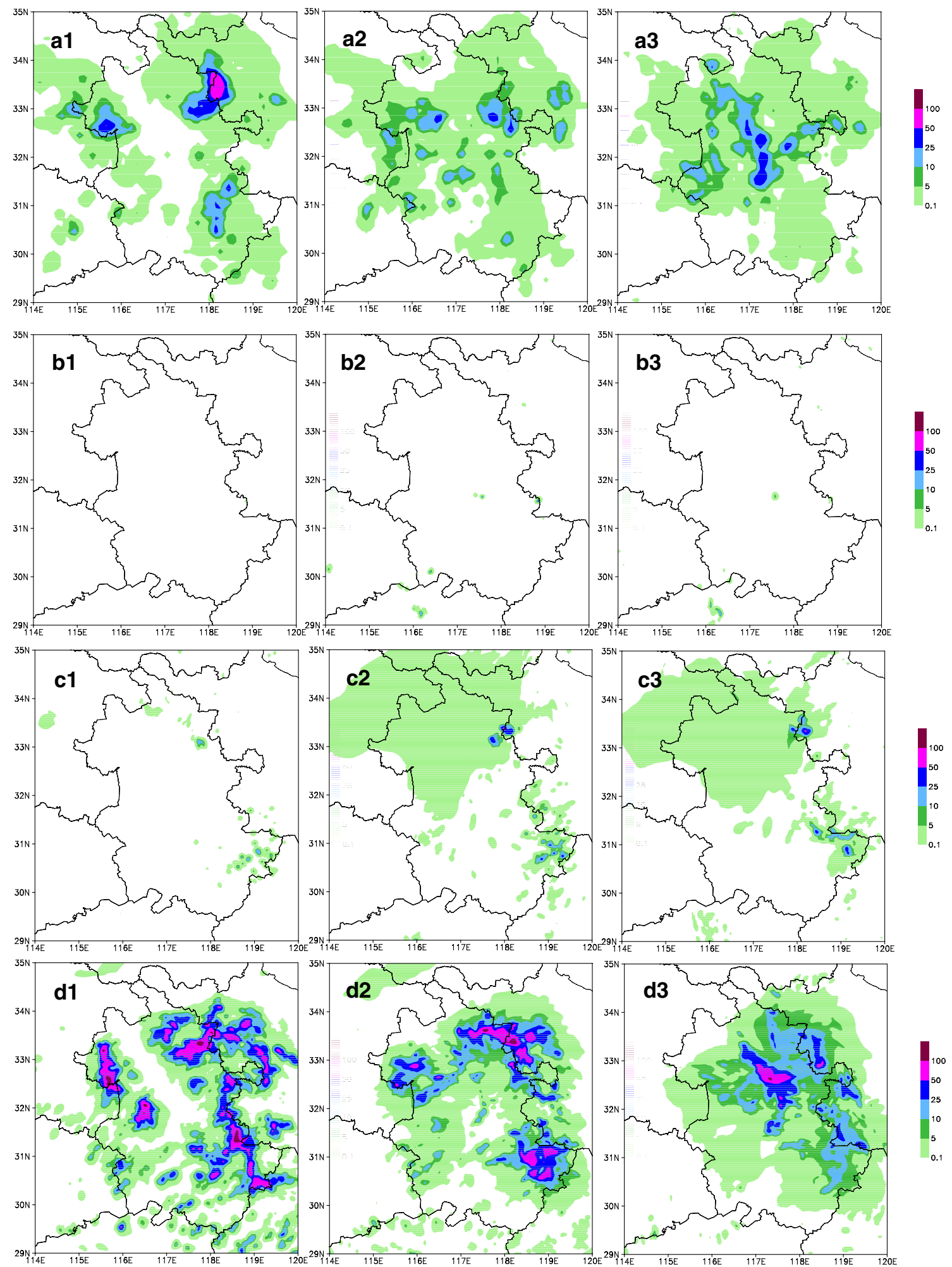

Fig. 8 Observed precipitation and simulated hourly rainfall in each experiment. (1, 2, and 3 denote the reflectivity at 1300 UTC, 1400 UTC, and 1500 UTC, respectively. a, b, c and d denote observation, CNTL experiment, RV_RF_S experiment and RV_RF_QV_S, respectively) 
$F=1-\frac{\frac{1}{N} \sum_{i-1}^{N}\left(p_{f i}-p_{o i}\right)^{2}}{\frac{1}{N}\left[\sum_{i-1}^{N} p_{f i}^{2}+\sum_{i-1}^{N} p_{o i}^{2}\right]}$,

where $F$ is the value of FSS, $P_{f i}$ and $P_{o i}$ are, respectively, the forecast probability and observation probability in the window region, and $N$ is the number of neighborhood windows in the study area. The FSS value is between 0 and 1 . If FSS is 1, it means that forecast is perfect. If FSS is 0 , it means a complete mismatch. When the width of the neighborhood window increases from 1 (the resolution of model) to $(2 n-1)$ ( $n$ is the number of grid points along the long axis of the window region), the FSS tends to be 1 . Under a certain threshold, the variation curve of the FSS with the window size can be obtained by taking the window size as the $\mathrm{X}$-axis and FSS as the Y-axis. By comparing different forecasting systems, the closer the FSS variation curve is to the upper left corner, the closer it is to one 1 in a smaller window region, that is, the better the forecast performance of this system will be.

$$
\begin{aligned}
& \mathrm{TS}=\frac{\mathrm{NA}}{\mathrm{NA}+\mathrm{NB}+\mathrm{NC}}, \\
& \mathrm{BIAS}=\frac{\mathrm{NA}+\mathrm{NB}}{\mathrm{NA}+\mathrm{NC}},
\end{aligned}
$$

where TS is the value of threat score, BIAS is the value of bias score. NA represents the number of stations (times) with correct forecast, NB represents the number of stronger stations (times), and $\mathrm{NC}$ represents the number of missing stations (times). The larger the TS value, the better the forecast effect.

\subsubsection{2 $\mathrm{b}$ Evaluation and analysis of precipitation forecast} results In this study, the thresholds selected for the hourly precipitation FSS are $0.1 \mathrm{~mm}, 5 \mathrm{~mm}, 10 \mathrm{~mm}$ and $25 \mathrm{~mm}$, respectively. Seen from Fig. 9, the FSS of the RV_RF_ QV_S experiment is significantly better than those of the CNTL and RV_RF_S experiment, and the precipitation FSS in each period is significantly improved. The results mean that after adjusting the water vapor, the precipitation FSS of the radar data assimilation is better than that without adjusting the water vapor in each period.

Seen from Fig. 10, by comparing the TS and BIAS scores from the RV_RF_QV_S experiment, RV_RF_S experiment, and CTRL experiment, the TS scores of the RV_RF_QV_S experiment are significantly improved. It should be pointed out the BIAS of the RV_RF_QV_S experiment is a bit higher when the 6-h precipitation is more than $30 \mathrm{~mm}$. The possible reason is that the retrieval water vapor content between 850 and $500 \mathrm{hPa}$ is larger than the observation, which is shown in Fig. 1. In the meanwhile, the RV_RF_S experiment and the CTRL experiment do not have the capacity to predict the heavy precipitation.

\subsection{Analysis of cycling assimilation}

\subsubsection{Reflectivity in the analysis field after cycling assimilation}

From Fig. 11a1-a3, by comparing the different experiments at 1300 UTC, the reflectivity in the analysis field of the RV_RF_QV_Cycle experiment is closer to the observation, and it makes a better simulation of the new-born convection echo. In addition, by comparing (Fig. 11b1-b3), we find the same result at 1400 UTC as at 1300 UTC.

\subsubsection{Reflectivity in the forecast field after cycling assimilation}

The impact of cycling assimilation on the reflectivity forecast is analyzed. Figures 12, 13 show the forecast reflectivity at different leading times by the RV_RF_QV_Cycle experiment and RV_RF_Cycle experiment, as well as their comparisons with observations. The conclusions from Fig. 7 are similar. It can be concluded that during this precipitation process, the RV_RF_Cycle experiment has a weaker ability to predict the reflectivity. The maximum reflectivity at the leading time of $10 \mathrm{~min}$ forecasted by the RV_RF_QV_Cycle experiment is close to the observation, but with the increase of leading time, its forecasting ability also obviously weakens. After $30 \mathrm{~min}$, the forecast echo shows a lag compared with the observation. At the same time, the forecast echoes in Figs. 12 and 13 are stronger than the observations.

\subsubsection{Precipitation forecast after cycling assimilation}

In the previous section, it has been found that the simulation result of water vapor retrieval in a single assimilation can maintain good for about $3 \mathrm{~h}$. Next, the effects of rapid cycling assimilation for the model prediction will be discussed.

By comparing and analyzing the accumulated precipitation during 1300-1400 UTC in Fig. 14a (observation), 14b (RV_RF_Cycle experiment) and 14c (RV_RF_QV_Cycle experiment), it is found that the RV_RF_Cycle experiment 

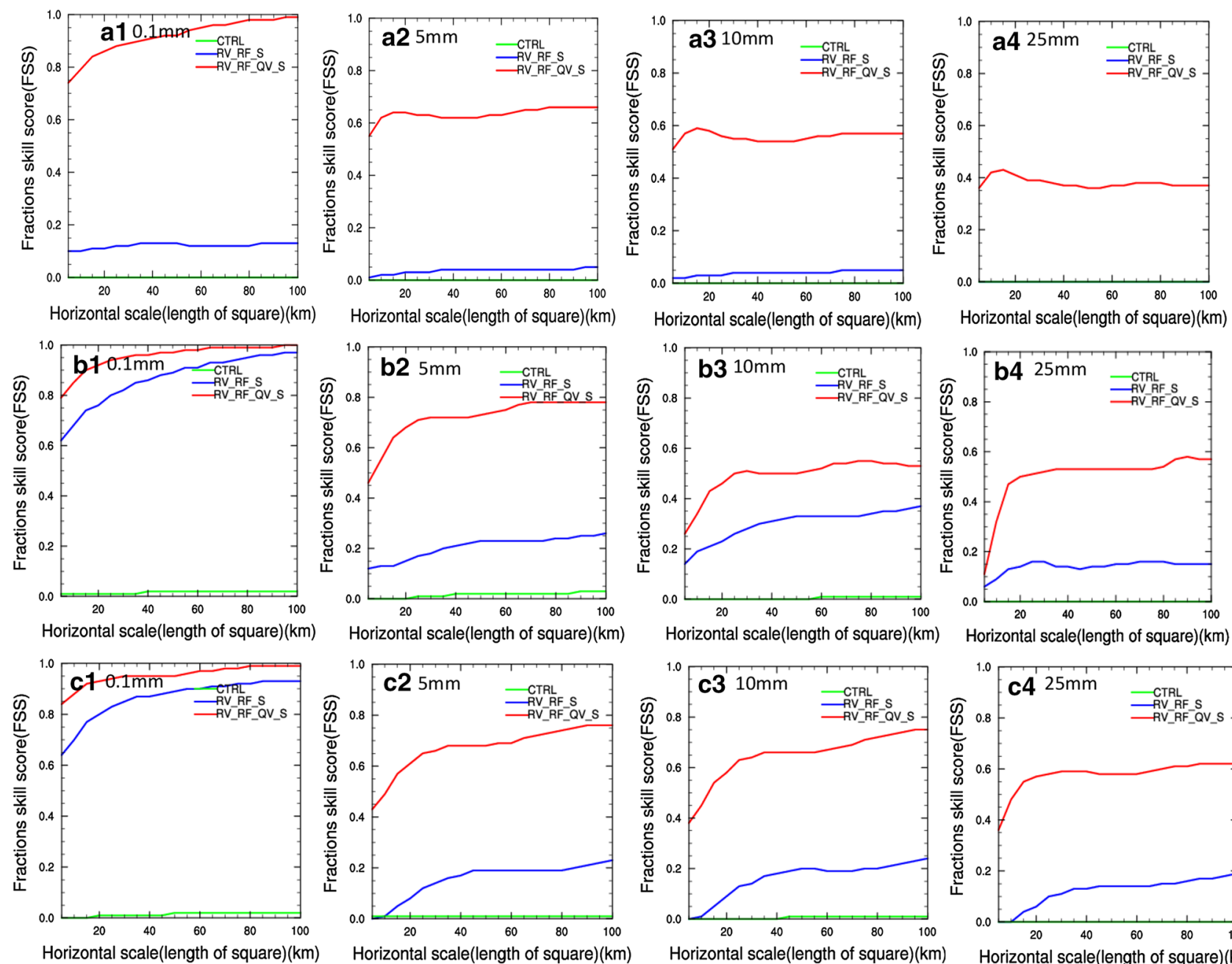

Fig. 9 Precipitation FSS of a single assimilation at different times under different thresholds. (a1-a4, b1-b4, and c1-c4 show the FSS at 1200-1300 UTC, 1300-1400 UTC, and 1400-1500 UTC, respectively, while 1, 2, 3 and 4 correspond to the precipitation thresholds

of $0.1 \mathrm{~mm}, 5 \mathrm{~mm}, 10 \mathrm{~mm}$ and $25 \mathrm{~mm}$, respectively. Red line represents the RV_RF_QV_S experiment, blue line represents the RV RF_S experiment, and green line represents the CNTL experiment)

Fig. 10 6-h Precipitation forecast skills of a single assimilation. a The TS and (b) the BIAS for the accumulated precipitation at $1200-1800 \mathrm{UTC}$
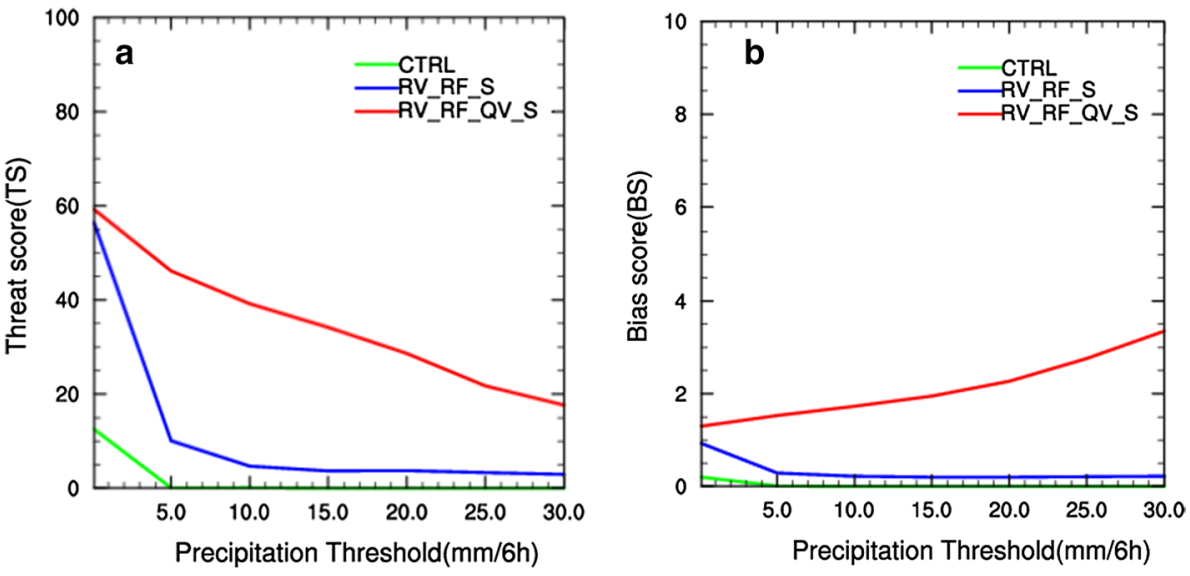

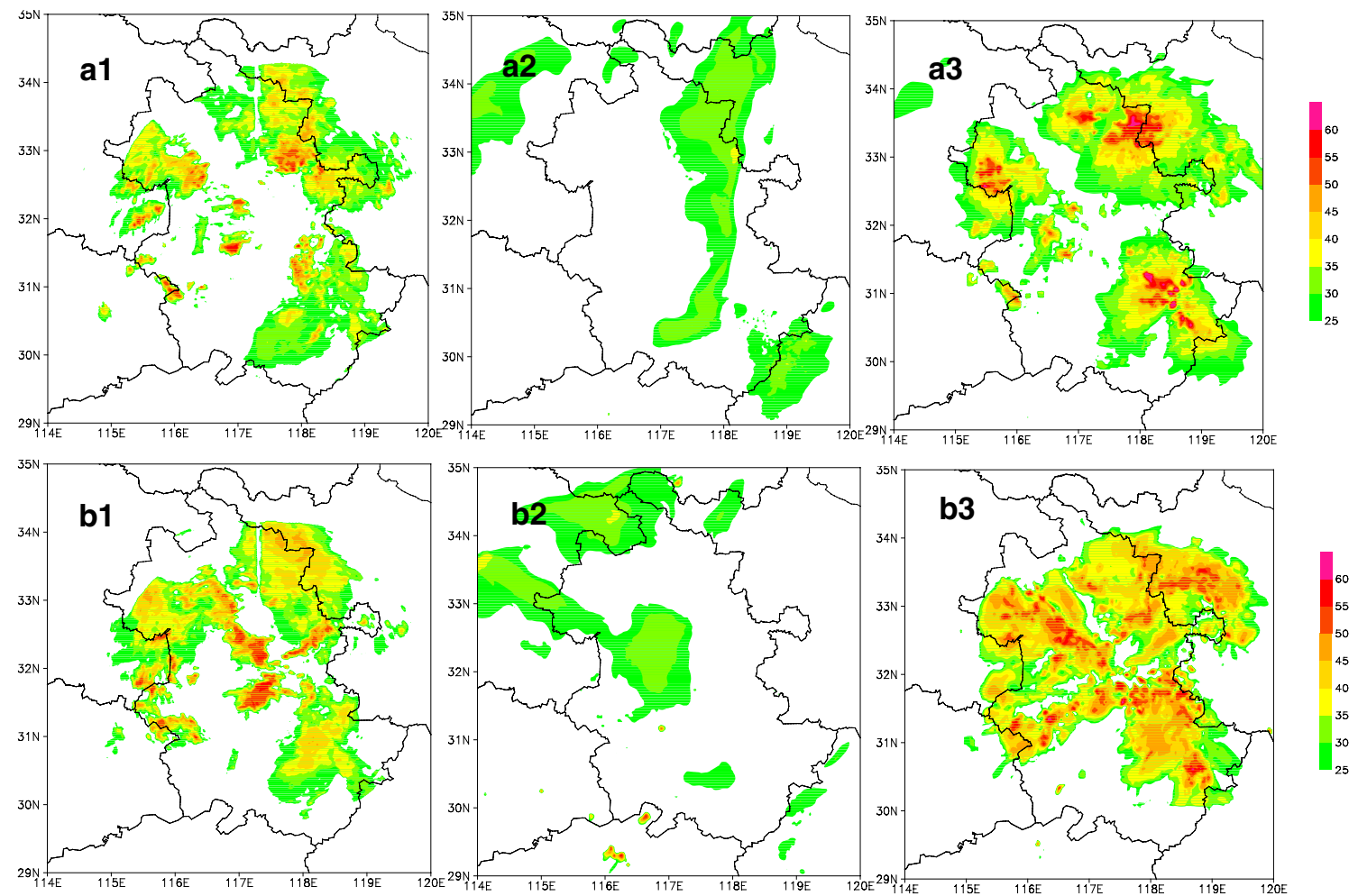

Fig. 11 The Maximum reflectivity in observation and analysis fields. (1, 2 and 3 denote observation, RV_RF_Cycle, and RV_RF_QV_Cycle, respectively. a and b denote 1300 UTC and 1400 UTC, respectively)

does not successfully predict the precipitation at 1300-1400 UTC. However, the area of heavy precipitation forecasted by the RV_RF_QV_Cycle experiment is closer to the observation, especially its forecast for the isolated precipitation area is better, while the forecast magnitude of the heavy rainfall is stronger than the observation.

By comparing and analyzing the accumulated precipitation during 1400-1500 UTC in Fig. 14d (observation), 14e (RV_RF_Cycle experiment) and 14f (RV_RF_QV_Cycle experiment), it can be found that the simulation results of the RV_RF_Cycle experiment are similar to the observations at the beginning, but the intensity and rainfall region are smaller. The RV_RF_QV_Cycle experiment is significantly better than the RV_RF_Cycle experiment for predicting the rainfall region and is closer to the observation, but the forecast rainfall intensity is still stronger than the observation.

\subsubsection{Evaluation and analysis of precipitation forecast results after cycling assimilation}

The precipitation thresholds are $0.1 \mathrm{~mm}, 5 \mathrm{~mm}, 10 \mathrm{~mm}$, and $25 \mathrm{~mm}$, respectively, and the FSS is performed on the hourly precipitation. In Fig. 15, there is not much difference in the FSS between RV_RF_QV_Cycle experiment and RV_RF_Cycle experiment when the precipitation is no more than $0.1 \mathrm{~mm}$. When the precipitation is greater than $5 \mathrm{~mm}$, the FSS of RV_RF_QV_Cycle experiment is significantly better than that of the RV_RF_Cycle experiment, especially in a small-scale area. This shows that cycling adjustment of water vapor and radar data assimilation can effectively improve the result of hourly precipitation prediction Fig. 16.

Figure 16 shows that the TS and BIAS scores from the the RV_RF_QV_Cycle experiment and RV_RF_Cycle 

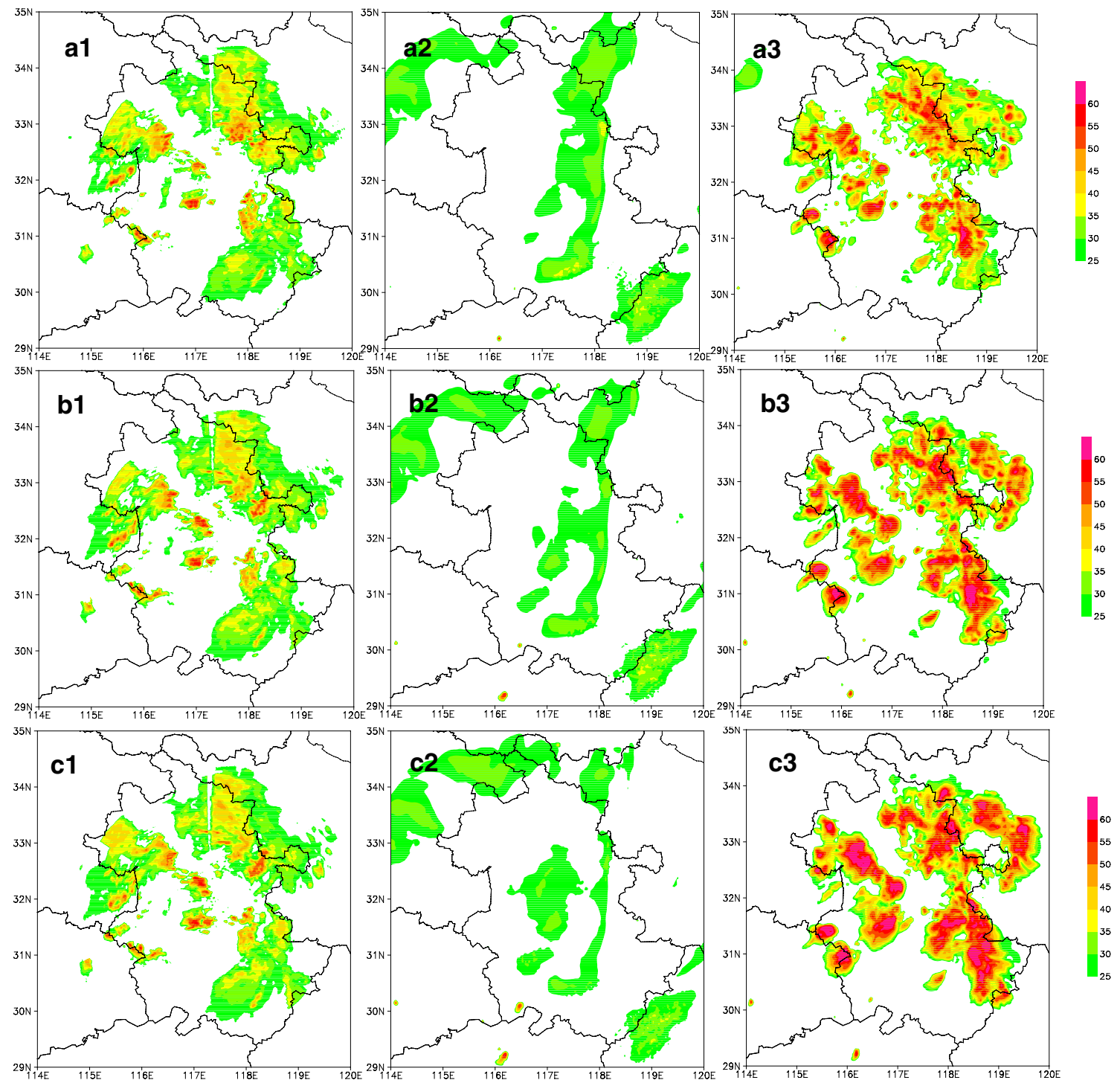

Fig. 12 The maximum reflectivity every $10 \mathrm{~min}$ initialized at 1300 UTC from cycling assimilation experiments. (1, 2 and 3 denote observation, RV_RF_Cycle and RV_RF_QV_Cycle, respectively. a, b and c Denote 1310 UTC, 1320 UTC and 1330 UTC, respectively)

experiment. It seems that the TS scores at different forecast leading times from the RV_RF_QV_Cycle experiment are significantly improved. Also note that the BIAS of the RV_RF_QV_Cycle experiment is less than RV_RF_Cycle experiment. Similar to the results from Song et al. 2019, Rodrigo et al. 2018, and Maiello et al. 2014.

\section{Summary and conclusion}

In this study, the radar radial velocity, reflectivity data are assimilated in the WRF-3DVAR assimilation system with retrieved water vapor by reflectivity data in the initial field. A convection process on July 26th, 2018 is selected for 

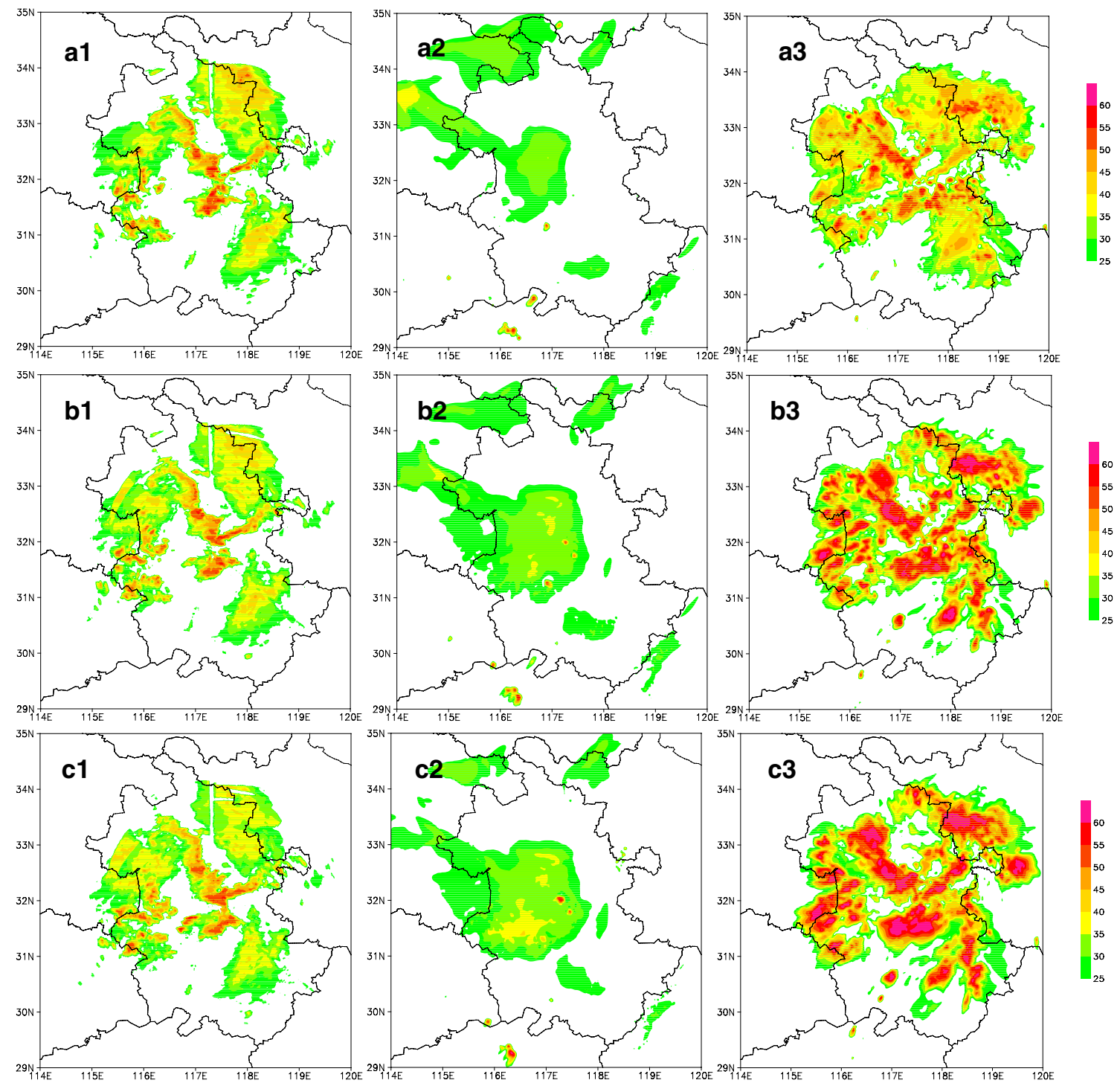

Fig. 13 The maximum reflectivity every $10 \mathrm{~min}$ initialized at 1400 UTC from assimilation cycling experiments. (1, 2 and 3 denote observation, RV_RF_Cycle and RV_RF_QV_Cycle, respectively. a, b and c Denote 1410 UTC, 1420 UTC and 1430 UTC, respectively)

numerical simulation experiments. And the conclusions are as follows.

(1) The experiment results show that the assimilation of radar data after adjusting the water vapor field can significantly increase the water vapor content at the model level in the analysis field, and it has a good corresponding relationship with the convection area, which can better simulate the distribution of rainbands. Therefore, the prediction of shorttime heavy rainfall can be improved.

(2) During this convection process, when the radar data are assimilated after adjusting the water vapor, the simulated reflectivity reflects the meso-scale characteristics more significantly, especially the new-born echo can be simulated clearly. The forecast of short-time heavy rainfall region is 

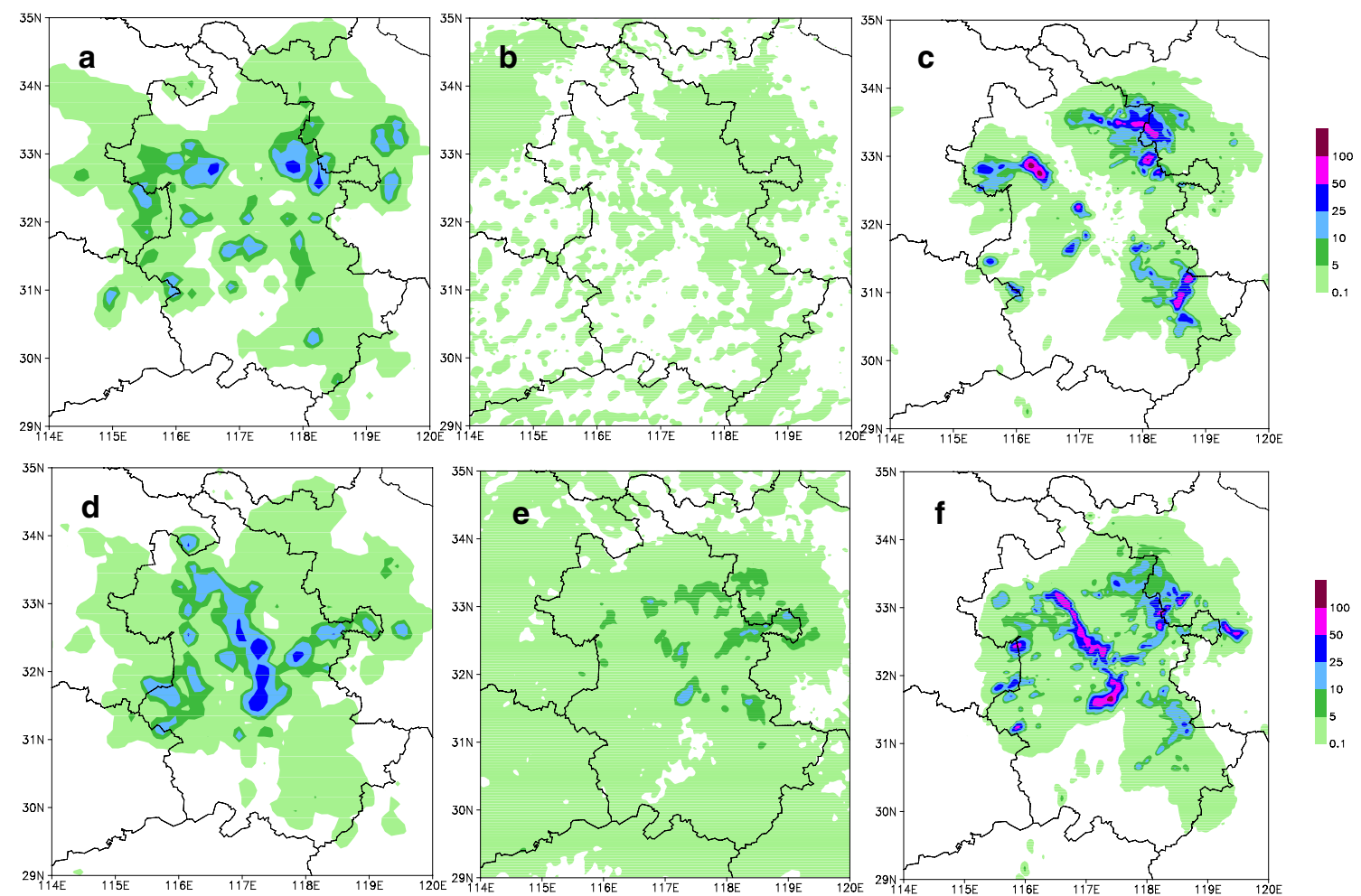

Fig. 14 a Observation and forecast of 1-h accumulated precipitation (the observation precipitation during 1300-1400 UTC; b the forecast rainfall during 1300-1400 UTC initialized at 1300 UTC by RV_RF Cycle experiment; $\mathbf{c}$ the forecast rainfall during 1300-1400 UTC initialized at 1300 UTC by RV_RF_QV_Cycle experiment; $d$ the observation precipitation precipitation during 1300-1400 UTC; e the forecast rainfall during 1400-1500 UTC initialized at 1400 UTC by RV_RF_Cycle experiment; f the forecast rainfall during 1400-1500 UTC initialized at 1400 UTC by RV_RF_QV_Cycle experiment)

In this study, it can be found the BIAS is a bit higher. The reasons may be that key fields such as temperature and humidity are harder to modify only using radar data assimilation and this retrieval algorithm only includes the statistical relationship between radar reflectivity and relative humidity at different temperatures. In fact, the reflectivity is the sum of the reflectivity of rain, snow water and graupel. Therefore, it is not perfect to retrieve relative humidity only by Doppler radar reflectivity. For example, the reflectivity observation. 

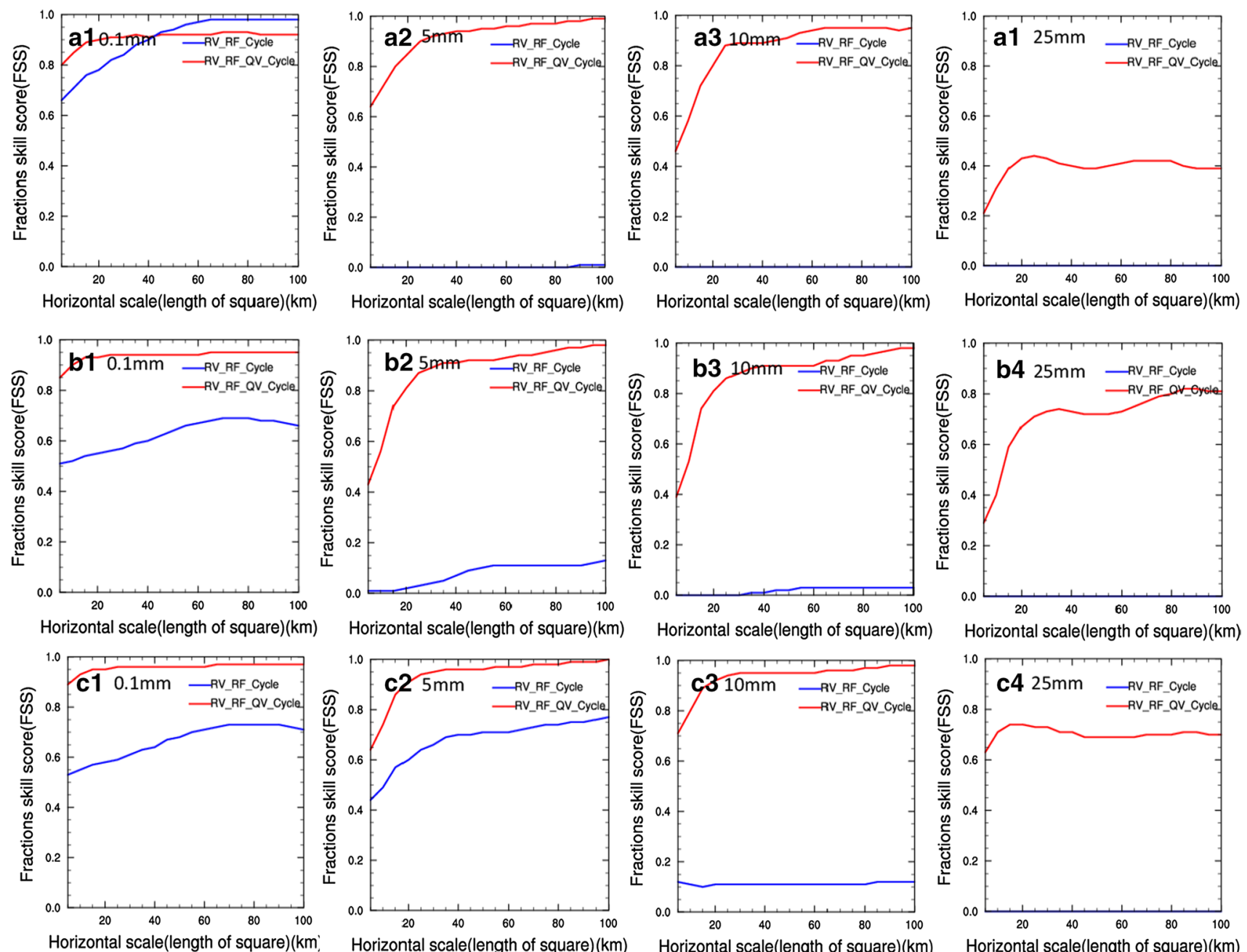

Fig. 15 FSSs of precipitation with different thresholds at different times after cycling assimilation. (1, 2, 3 and 4 denote precipitation thresholds of $0.1 \mathrm{~mm}, 5 \mathrm{~mm}, 10 \mathrm{~mm}$ and $25 \mathrm{~mm}$, a denotes the forecast precipitation in 1300-1400 UTC initialized at 13:00 UTC,

is larger in the hail in summer convection, but the corresponding precipitation is not stronger any time. Thus, the water vapor content $\mathrm{QV}$ of WRF model is adjusted higher in the strong echo area, and the precipitation predicted by the model is stronger, and the false alarm (NB) is higher, which makes the bias score higher.

Meanwhile, only one case was used for the assimilation of retrieved water vapor. Due to different factors such as different seasons, different elements affected by different weather processes and the difference of the initial value error, more cases are needed to verify the reasonability of the water vapor retrieval. Meanwhile, in the strong echo region, the

b denotes the forecast precipitation in 1400-1500 initialized at 1300 UTC, and c denotes the forecast precipitation in 1400-1500 initialized at 1400 UTC. The red line denotes the RV_RF_QV_Cycle experiment, and the blue line denotes the RV_RF_Cycle experiment)

intensity of the simulated reflectivity and the short-time heavy rainfall are stronger.

Therefore, in the future, using the dual polarization radar data, the relationship between radar reflectivity $(Z)$, differential reflectivity $Z_{\mathrm{DR}}$ and relative humidity at different phase states will be calculated, the local heavy rainfall forecast will be improved. The variation of vertical velocity and temperature in the strong echo region must be considered in the initial filed. Further experiments with more cases over extended periods and assimilating more observations (as well as other remote sensing observations 
Fig. 16 TSs and BIAS of precipitation with different thresholds at different times after cycling assimilation for the accumulated precipitation $(\mathbf{a} 1)$ from 1300 to 1800 UTC initialized at 1300 UTC, a2) from 1400 to $1900 \mathrm{UTC}$ initialized at 1400 UTC. b1-b2 same as a1-a2, but for BIAS
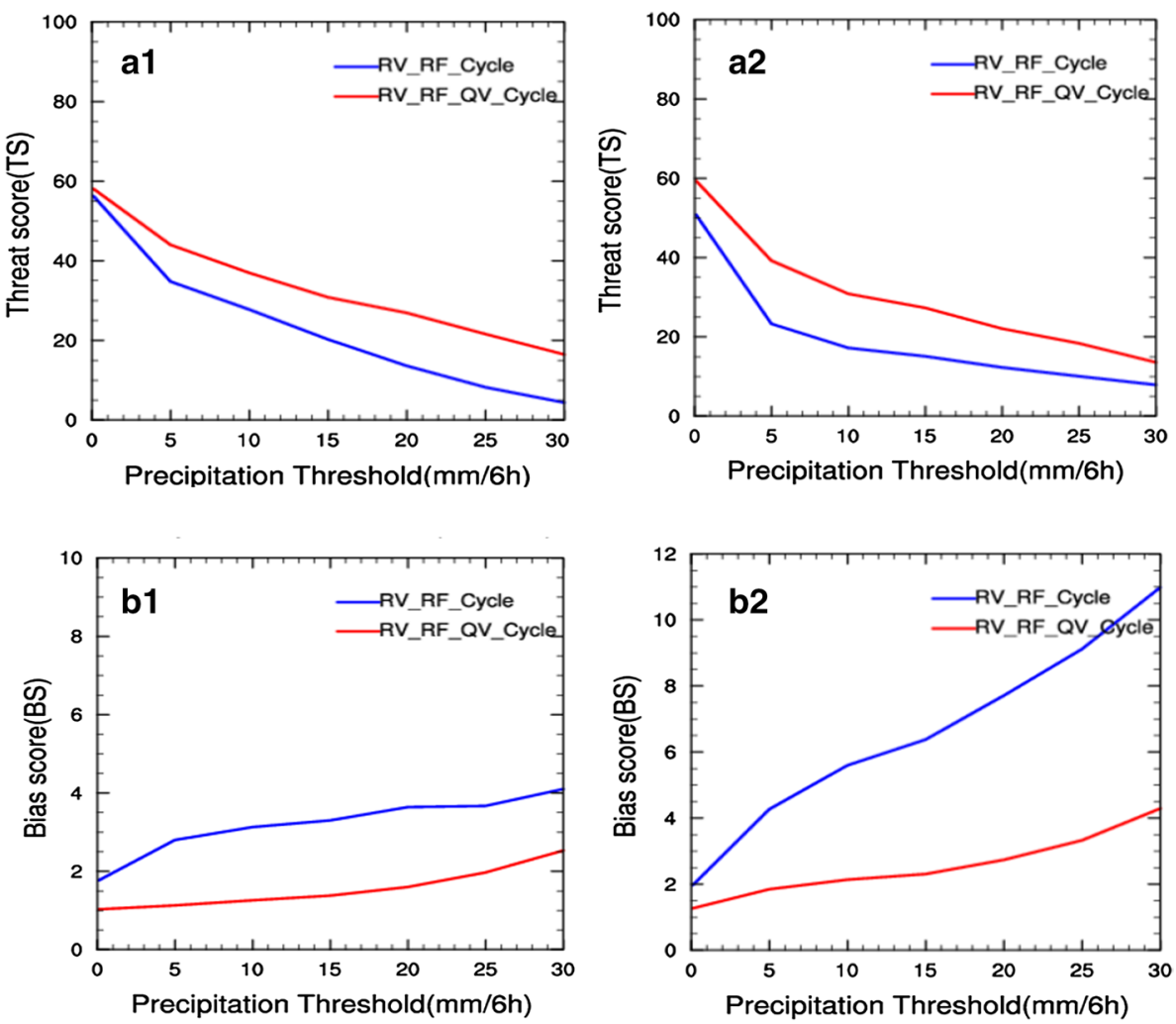

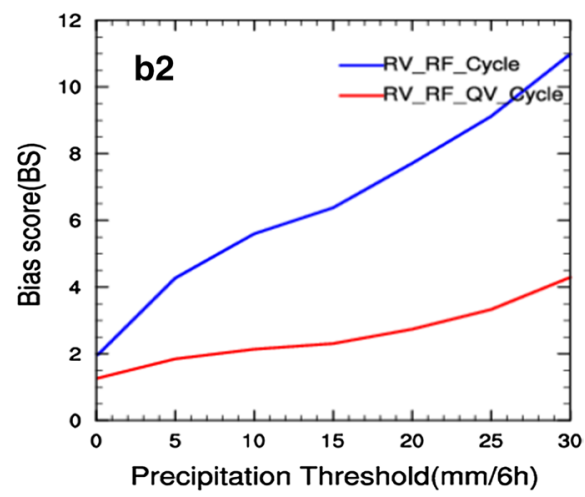

such as radiance by satellite; e.g., Xu et al. 2014, 2015a, b, 2016a) are needed to verify the generality of the results.

Acknowledgement This research was primarily supported by the Shanghai Typhoon Research Foundation (TFJJ201909), the Anhui Meteorological Bureau Science Development Foundation (KM201902).

Open Access This article is licensed under a Creative Commons Attribution 4.0 International License, which permits use, sharing, adaptation, distribution and reproduction in any medium or format, as long as you give appropriate credit to the original author(s) and the source, provide a link to the Creative Commons licence, and indicate if changes were made. The images or other third party material in this article are included in the article's Creative Commons licence, unless indicated otherwise in a credit line to the material. If material is not included in the article's Creative Commons licence and your intended use is not permitted by statutory regulation or exceeds the permitted use, you will need to obtain permission directly from the copyright holder. To view a copy of this licence, visit http://creativecommons.org/licenses/by/4.0/.

\section{References}

Achenafi T, Yihun T, Dereje H et al (2019) Impacts of land surface model and land use data on WRF model simulations of rainfall and temperature over Lake Tana Basin. Ethiopia Heliyon 5:e02469

Brewster KA (2015) An updated high resolution hydrometeor analysis system using radar and other data 27th Conf on Weather Analysis and Forecasting 23rd Conf on numerical weather prediction Chicago IL. Amer Meteor Soc 31:19

Caumont O, Ducrocq V, Wattrelot E et al (2010) 1D13DVar assimilation of radar reflectivity data: a proof of concept. Dynamic Meteorol Oceanogr 62:173-187

Courtier P, Thépaut JN, Hollingsworth A (1994) A strategy for operational implementation of 4D-Var, using an incremental approach. Quart J Roy Meteor Soc 120:1367-1387

Dowell DC, Wicker LJ, Snyder C (2011) Ensemble Kalman filter assimilation of radar observations of the 8 May 2003 Oklahoma City supercell: Influences of reflectivity observations on stormscale analyses. Mon Wea Rev 139:272-294

Fabry F, Meunier V (2020) Why are radar data so difficult to assimilate skillfully? Mon Wea Rev 148:2819-2835

Gao JD, Brewster K (2004) A three-dimensional variational data analysis method with recursive filter for Doppler radars. J Atmos Ocea Tech 21:457-469

Gao JD, Stensrud DJ (2012) Assimilation of reflectivity data in a convective-scale, cycled 3DVAR framework with hydrometeor classification. J Atmos Sci 69:1054-1065

Gao JD, Stensrud DJ (2014) Some observing system simulation experiments with a hybrid 3DEnVAR system for storm-scale radar data assimilation. Mon Wea Rev 142:3326-3346

Gao JD, Fu CH, Stensrud DJ et al (2016) OSSEs for an ensemble 3DVAR data assimilation system with radar observations of convective storms. J Atmos Sci 73:2403-2426

Gauthier P, Charette C, Fillion L et al (1999) Implementation of a 3D variational data assimilation system at the Canadian Meteorological Centre Part I The global analysis. Atmos Ocean 37:103-156

Ge G, Gao JD, Xue M (2013) Impacts of assimilating measurements of different state variables with a simulated supercell storm and three-dimensional variational method. Mon Wea Rev 141:2759-2777 
Gilmore MS, Straka JM, Rasmussen EN (2004) Precipitation and evolution sensitivity in simulated deep convective storms: comparisons between liquid-only and simple ice and liquid phase microphysics. Mon Wea Rev 132:1897-1916

Honda Y, Nishijima M, Koizumi K et al (2005) A pre-operational variational data assimilation system for a non-hydrostatic model at the Japan meteorological agency: formulation and preliminary results. Quart J Roy Meteor Soc 131:3465-3475

Hu M, Xue M, Brewster K (2006) 3DVAR and cloud analysis with WSR-88D Level-II data for the prediction of the Fort Worth, Texas, Tornadic thunderstorms. Part I: cloud analysis and its impact. Mon Wea Rev 134:699-721

Huang XY, Xiao Q, Barker DM et al (2009) Four-dimensional variational data assimilation for WRF: formulation and preliminary results. Mon Wea Rev 137:299-314

Kuo YH, Xiao Q, Sun J et al (2005) Assimilation of Doppler radar observations with a regional 3DVAR system: impact of Doppler velocities on forecasts of a heavy rainfall case. J Appl Meteorol Res 44:768-788

Lai A, Gao JD, Koch SE et al (2019) Assimilation of radar radial velocity, reflectivity, and pseudo-water Vapor for convective-scale NWP in a variational framework. Mon Wea Rev 147:2877-2900

Li Y, Wang X, Xue M (2012) Assimilation of radar radial velocity data with the WRF hybrid ensemble-3DVAR hybrid system for the prediction of Hurricane Ike (2008). Mon Wea Rev 140:3507-3524

Lin YL, Farley RD, Orville HD (1983) Bulk parameterization of the snow field in a cloud model. J Climate Appl Meteor 22:1065-1092

Lorenc AC (2000) The Met Office global three-dimensional variational data assimilation scheme. Quart J Roy Meteor Soc 126:2991-3012

Maiello I, Ferretti R, Gentile S, Montopoli M, Picciotti E, Marzanoand FS, Faccani C (2014) Impact of radar data assimilation for the simulation of a heavy rainfall case in central Italy using WRF3DVAR. Atmos Meas Tech 7:2919-2935

Montmerle T, Faccani C (2009) Mesoscale assimilation of radial velocities from Doppler Radars in a preoperational framework. Mon Wea Rev 137:1939-1953

Parrish DF, Derber JC (1992) The National Meteorological Center's spectral statistical-interpolation analysis system. Mon Wea Rev 120:1747-1763

Roberts NM, Lean HW (2008) Scale-selective verification of rainfall accumulations from high-resolution forecasts of convective events. Mon Wea Rev 136:78-97

Rodrigo C, Kim S, II Hyo J (2018) Sensitivity study of WRF numerical modeling for forecasting heavy rainfall in Sri Lanka. Atmosphere 9:378. https://doi.org/10.3390/atmos9100378

Schenkman AD, Xue M, Shapiro A et al (2011) The Analysis and prediction of the 8-9 May 2007 Oklahoma Tornadic Mesoscale convective system by assimilating WSR-88D and CASA radar data using 3DVAR. Mon Wea Rev 139:224-246

Shen FF, Min JZ (2015) Assimilating AMSU-A radiance data with the WRF hybrid En3DVAR system for track predictions of typhoon megi (2010). Adv Atmos Sci 32:1231-1243

Shen FF, Min JZ (2016) Assimilation of radar radial velocity data with the WRF hybrid ETKF-3DVAR system for the prediction of Hurricane Ike (2008). Atmos Res 169:127-138

Shen FF, Xue M, Xu DM et al (2017) A comparison between EDAEnVar and ETKF-EnVar data assimilation techniques using radar observations at convective scales through a case study of Hurricane Ike (2008). Meteorol Atmos Phys 130:649-666

Shen FF, Xue M, Min JZ (2017) A comparison of limited-area 3DVAR and ETKF-En3DVAR data assimilation using radar observations at convective scale for the prediction of Typhoon Saomai (2006). Meteorol Appl 24:628-641
Shen FF, Xu DM, Min JZ (2019) Effect of momentum control variables on assimilating radar observations for the analysis and forecast for Typhoon Chanthu (2010). Atmos Res 230:104622

Shen FF, Xu DM, Min JZ et al (2019) Assimilation of radar radial velocity data with the WRF Hybrid 4DEnVar system for the prediction of Hurricane Ike (2008). Atmos Res 234:104771

Song HJ, Lim B, Joo S (2019) Evaluation of rainfall forecasts with heavy rain types in the high-resolution unified model over South Korea. Wea Forecast 34:1277-1293

Sugimoto S, Crook NA, Sun J et al (2009) An Examination of WRF 3DVAR radar data assimilation on its capability in retrieving unobserved variables and forecasting precipitation through observing system simulation experiments. Mon Wea Rev 137:4011-4029

Sun J, Crook NA (1997) Dynamical and microphysical retrieval from Doppler radar observations using a cloud model and its adjoint. Part I: model development and simulated data experiments. J Atmos Sci 54:1642-1661

Sun J, Crook NA (1998) Dynamical and microphysical retrieval from Doppler radar observations using a cloud model and its adjoint. Part II: retrieval experiments of an observed Florida convective storm. J Atmos Sci 55:835-852

Sun J, Wang HL (2013) Radar data assimilation with WRF 4D-Var. Part II: comparison with 3D-Var for a squall line over the U.S. Great Plains Mon Wea Rev 141:2245-2264

Tanamachi RL, Wicker LJ, Dowell DC et al (2013) EnKF assimilation of high-resolution, mobile Doppler radar data of the 4 May 2007 greensburg, kansas, supercell into a numerical cloud model. Mon Wea Rev 141:625-648

Tong M, Xue M (2005) Ensemble Kalman filter assimilation of Doppler radar data with a compressible nonhydrostatic model: OSS experiments. Mon Wea Rev 133:1789-1807

Wang X (2011) Application of the WRF hybrid ETKF-3DVAR data assimilation system for hurricane track forecasts. Wea Forecast $26: 868-884$

Wang Y, Wang X (2017) Direct assimilation of radar reflectivity without tangent linear and adjoint of the nonlinear observation operator in the GSI-based EnVar system: methodology and experiment with the 8 May 2003 Oklahoma City tornadic supercell. Mon Wea Rev 145:1447-1471

Wang X, Barker DM, Snyder C et al (2008a) A hybrid ETKF-3DVAR data assimilation scheme for the WRF model. Part I: observing system simulation experiment. Mon Wea Rev 136:5116-5131

Wang X, Barker DM, Snyder C et al (2008b) A hybrid ETKF3DVAR data assimilation scheme for the WRF model. Part II: Real observation experiments. Mon Wea Rev 136:5132-5147

Wang HL, Sun J, Fan S et al (2013) Indirect assimilation of radar reflectivity with WRF 3D-Var and Its impact on prediction of four summertime convective events. J Appl Meteorol Res Climatol 52:889-902

Wang HL, Sun J, Zhang X et al (2013) Radar data assimilation with WRF 4D-Var. Part I: system development and preliminary testing. Mon Wea Rev 141:2224-2244

Wang X, Parrish D, Kleist D et al (2013) GSI 3DVar-based ensemble-variational hybrid data assimilation for NCEP global forecast system: single-resolution experiments. Mon Wea Rev 141:4098-4117

Wattrelot E, Caumont O, Mahfouf JF (2014) Operational implementation of the 1D3D-Var assimilation method of radar reflectivity data in the AROME model. Mon Wea Rev 142:1852-1873

Xu DM, Liu ZQ, Huang XY et al (2013) Impact of assimilating IASI radiance observations on forecasts of two tropical cyclones. Meteorol Atmos Phys 122:1-18

Xu DM, Huang XY, Liu ZQ et al (2014) Comparisons of two cloud detection schemes for infrared radiance observations. Atmos Oceanic Sci Lett 7:358-363 
Xu DM, Auligné T, Huang XY (2015) A validation of the multivariate and minimum residual method for cloud retrieval using radiance from multiple satellites. Adv Atmos Sci 32:349-362

Xu DM, Huang XY, Liu ZQ et al (2015) Impact of assimilating radiances with the WRFDA ETKF/3DVAR hybrid system on the prediction of two typhoons (2012). J Meteor Res 29:28-40

Xu DM, Auligné T, Descombes G et al (2016) A method for retrieving clouds with satellite infrared radiances using the particle filter. Geosci Model Dev 9:3919-3932

Xu DM, Min JZ, Shen FF et al (2016) Assimilation of MWHS radiance data from the FY-3B satellite with the WRF Hybrid-3DVAR system for the forecasting of binary typhoons. J Adv Model Earth Syst 8:1014-1028

Xu DM, Shen FF, Min JZ (2019a) Effect of adding hydrometeor mixing ratios control variables on assimilating radar observations for the analysis and forecast of a typhoon. Atmosphere 10:415

Xu DM, Shen FF, Min JZ (2019b) Effect of background error tuning on assimilating radar radial velocity observations for the forecast of hurricane tracks and intensities. Meteorol Appl 27:e1820

Xue M, Wang DH, Gao JD et al (2003) The advanced regional prediction system (ARPS), storm-scale numerical weather and data assimilation. Meteor Atmos Phys 82:139-190

Zhang J (1999) Moisture and diabatic initialization based on radar and satellite observations dissertation. University of Oklahoma, Oklahoma
Zhang M, Zhang FQ (2012) E4DVar: Coupling an ensemble Kalman filter with four-dimensional variational data assimilation in a limited-area weather prediction model. Mon Wea Rev 140:587-600

Zhang FQ, Snyder C, Sun J (2004) Impacts of initial estimate and observation availability on convective-scale data assimilation with an ensemble Kalman filter. Mon Wea Rev 132:1238-1253

Zhang FQ, Weng Y, Sippel JA et al (2009) Cloud-resolving hurricane initialization and prediction through assimilation of Doppler Radar observations with an ensemble kalman filter. Mon Wea Rev 137:2105-2125

Zhang M, Zhang FQ, Huang XY et al (2011) Intercomparison of an ensemble kalman filter with three- and four-dimensional variational data assimilation methods in a limited-area model over the Month of June 2003. Mon Wea Rev 139:566-572

Zupanski M, Zupanski D, Vukicevic T et al (2005) CIRA/CSU fourdimensional variational data assimilation system. Mon Wea Rev 133:829-843

Publisher's Note Springer Nature remains neutral with regard to jurisdictional claims in published maps and institutional affiliations. 